\title{
Ein freier Nachmittag!
}

Die warme Frühlingssonne hat nicht nur in Wald und Auen, sondern auch im Wasser ein ebenso buntes als bewegtes Leben hervorgerufen und ist Jedem zu rathen, der ein bischen Nässe nicht scheut, beim Spatziergange seine Schritte nach einem Sumpfe zu lenken, um daselbst Erscheinungen zu beobachten, die im höchsten Grade entzücken, auf den ersten Augenblick sogar in Verwunderung setzen müssen. Winzige Wasserflöhe tummeln sich im seichten Wasser, verfolgt von anderen grösseren Räubern. Auf der Obertäche rennen langfüssige und schmalleibige, in der Tiefe schwimmen ruderfüssige glatte Wasserwanzen herum, und an den Pflanzenstengeln auf und nieder klettern rastlos die Wassermilben. Ein Schauspiel, das jeden Beschauer, wenn auch die Form dieser Wesen nicht sonderlich anspricht, besonders nach der langen Winterruhe und der Einförmigkeit des ihn sonst bindenden Geschäftes, entzücken muss. Ausser dem gemischten Treiben vieler gewandter Läufer -, Kletter -, Rücken -, Bauch und Seitenschwimmer ergötzt uns das Spiel silberglänzender Luftblasen, die gleich Ballons, von unsichtbaren Mächten der Tiefe entsendet, lustig die Gewässer durchkreuzen. Aber siehe! Seit wann pflegen Luftblasen, allen Gesetzen der Schwere zuwider, von der Oberfläche zum Boden hinabzusinken? Beobachten wir genau, so werden wir bald ein Thierchen entdecken, das mit der Luftblase in Verbindung, oder vielmehr von derselben zum Theil umflossen, mit aller Schnelligkeit dem Boden des Gewässers zurudert. Dieses wunderbare Thierchen präsentirt sich als Argyroneta aquatica, die Wasserspinne.

Von unscheinbarem Aussehen zwar ist doch an diesem kleinen Wesen Alles äusserst wunderbar. Wie die übrigen Spinnen ist anch diese eine Luftathmerin und besitzt ausser ein paar kleinen unvollkommenen Lungen noch zahlreiche, diesen Insecten eigne Athmungsorgane (Tracheen), die als äusserst zarte Röhrchen den ganzen Leib durchziehen. Will unser Taucher in die Tiefe gehen, so versieht er sich mit 
einem Vorrath atmosphärischer Luft, indem er seinen Leib, oder richtiger, sie ihren Hinterleib über die Oberfläche des Wassers erhebt und so dann schnell unter dasselbe zurückzieht. Dass hierbei die Luft aber nicht in kleinen, isolirten Bläschen, wie sonst beim Eintauchen haariger Körper in Wasser, sondern in zusammenhängender Masse am Leibe haftet, lässt schliessen, dass hierbei eine willkührliche Thätigkeit zu Grunde liege.

Es ist anzunehmen, dass dieses Individuum eine fettige Flüssigkeit aussondert und über den ganzen- Leib schweissartig ergiesset, wähṛend sie die früher in sich aufgenommene Luft aus den Luftröhrchen heraustreibt, welche dann in Form einer von unsichtbaren Häutchen umkleideten Blase ihren Körper umhüllt. Nachdem auf diese Weise das eigenthümliche Blasenspiel erklärt und hierdurch der Spinne ein längerer Aufenthalt in Wasser ermöglicht ist, beginnt sie, nahe dem Grunde, zwischen Stengeln von Wasserpflanzen starke Faden zu spinnen and verfertigt nach und nach ein wasserdichtes horizontales Gewebe. Ist auch diese planeartige Decke gebildet, so kommt das Insect wiederholt an die Oberfï̈ohe, versieht sich mit einem tüchtigen Luftvorrath, taucht in die Tiefe und entledigt sich unter der ausgespannten Fläche der mitgenommenen Luft, indem sie diese mit den Hinterfüssen von sich streift. Die so frei gewordene Luft wird in ihrem Bestreben, aufwärts zu steigen, durch den Widerstand des zarten Gewebes aufgehalten und wölbt hierdurch dasselbe. Von dem fleissigen Thiere wird dieses Mannöver so lange fortgesetzt, bis das glockenförmige Gebilde die Grösse einer Nuss erhalten hat, und schliesslich mit einem Boden von gleichem Material, der nur ein kleines rundes Schlüpfloch hat, verschlossen.

Unser arbeitsames Vorbild hat sich auf diese Weise ein Domicil geschaffen, in welches das* Wasser nur bis zu geringer Höhe einzudringen vermag und das nur zeitweise mit frischer Luft versorgt zu werden braucht.

In diesem Luftschlosse (in des Wortes edelster Bedeutung), welches der Bewohner blos zur Winterzeit dauernd 
verlässt, um diesen rauhen Gast in Löchern der Erde, Schneckenhäusern etc. besser entgegentreten zu können, führt die Wasserspinne ein behagliches, einsiedlerisches Leben. Ihre Speise besteht in lebenden Insecten, an welchen es ihr in nächster Umgebung nicht mangelt. Alle Spinnen und somit anch diese Species sind Räuber, die ihre Beute überfallen, mit einem Bisse lähmen und dann gemächlich aussaugen. Männchen nnd Weibchen werden nie in einer und derselben Behausung gefunden, leben diöcisch und verfolgen sich in der Regel, so bald Eins das Gebiet des Anderen zu betreten wagt. Hier unten im kühlen Grunde legt das Weibchen ihre Eier und geniesst die Freuden und Leiden der Liebe. Harrend sitzt das Männchen an der Schwelle seines Hauses. Da naht sich die Geliebte, jetzt gilt es nicht zärtliches Kosen und Schmachten, es gilt einer Werbung im Sprung und mit Gewalt. Ist der grosse Wurf gelungen, dann muss sich unser Held weder mit Präliminarien aufhalten, noch seine Sinne zu sehr vom Liebesrausch umnebeln lassen, denn entflieht er nicht eilig wie er gekommen, so wird er ausgesogen bis auf die Haut. Ein seltsamer, wenngleich nicht ausschliesslich auf das Geschlecht der achtfüssigen Geschöpfe beschränkter Lohn der Liebe.

O. Facilides, in Zwickau. 